\title{
Influence of COVID -19 Pandemic on Acute Coronary Syndrome and Management of ST segment elevation Myocardial infarction in a single Cardiac intervention center in Kingdom of Bahrain A glimpse from the gulf region
}

\section{Fawaz Bardooli*, MD, Jasim Hasan, MD, Abdulkarim Abdulrahman, MD Shereen Al shaikh, MD}

Mohamed bin Khalifa bin Salman Al Khalifa Cardiac Center, Riffa Bahrain

*Corresponding author: Fawaz Bardooli, Mohamed bin Khalifa bin Salman Al Khalifa Cardiac Center, Riffa Bahrain Received date: Augusł 24, 2020; Accepted date: September 04, 2020; Published date: September 10, 2020

Citation: Bardooli F., Hasan J., Abdulrahman A., Shereen Al shaikh., (2020) Influence of COVID -19 pandemic on acute coronary syndrome and management of ST segment elevation myocardial infarction in a single cardiac intervention center in Kingdom of Bahrain A glimpse from the gulf region. J, Clinical Cardiology and Cardiovascular Interventions, 3(7); Doi:10.31579/2641-0419/077

Copyright: (C) 2020 Fawaz Bardooli, This is an open access article distributed under the Creative Commons Attribution License, which permits unrestricted use, distribution, and reproduction in any medium, provided the original work is properly cited.

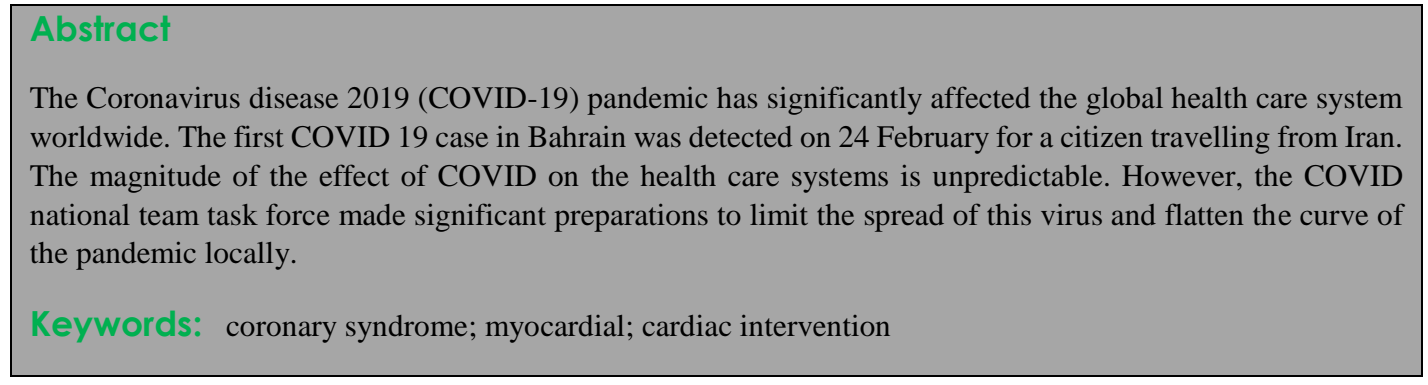

\section{Introduction}

The Coronavirus disease 2019 (COVID-19) pandemic has significantly affected the global health care system worldwide. The first COVID 19 case in Bahrain was detected on 24 February for a citizen travelling from Iran. The magnitude of the effect of COVID on the health care systems is unpredictable. However, the COVID national team task force made significant preparations to limit the spread of this virus and flatten the curve of the pandemic locally. In Bahrain, the only cardiac center performing percutaneous and surgical cardiac interventions is Sh Mohammed bin Khalifa Cardiac Center (MKCC). This center receives direct admissions through emergency medical department (EMD) as well other cardiology referring hospitals.

\section{Protocol and Methods:}

In attempt to preserve resources, including personal protection equipment (PPE) and direct the work force to COVID centers. Certain protocols were adopted to maintain safe environment for patients and health care workers in the hospital. Elective cardiac procedures, including coronary angiography and percutaneous coronary intervention (PCI) for stable coronary artery disease were deferred (1). Thrombolysis with metalyse becomes the first line therapy for ST elevation Myocardial infarction (STEMI) unless contraindicated. Low grace score acute coronary syndromes (ACS) were treated with a conservative approach. If medical therapy failed, the patient was taken to the cardiac catheterization laboratory after ascertaining his/her COVID status. Cardiac catheterization laboratories were separately labelled as COVID and Non COVID labs with high-efficiency particulate air (HEPA) filter.

\section{Results and conclusion:}

Preliminary data from different countries suggested a reduction in STEMI presentations at the inception of the COVID-19 pandemic $^{2-3}$ However, there is no such data representative of the gulf region. Moreover, it remains to be determined what effect COVID-19 has had on total cardiovascular admissions and the management of STEMI. Data on COVID-19 cases and cardiac admissions was collected retrospectively between 5 February 2020 and 1 May 2020. The COVID19 restrictions were started in the cardiac Centre on March 19. Following the restrictions, the total number of admissions reduced from 375 to 79 , out of which 29 were ST elevation and 36 were non ST elevation myocardial infarction (NSTEMI). (Corresponding to a reduction of $79 \%$ in total cardiac medical admissions, 57\% in STEMI and 60\% in NSTEMI from the pre-COVID restrictions). (Figure 1a) While the number of total admissions during the COVID era reduced given the protocol adapted and the increasing number of daily COVID cases detected (Figure 1b), the reduction in numbers of STEMI patients remain a mystery(Figure 1c). Our results are in line with a recently published analysis from STEMI activations for 9 high-volume US centers [3]. The kingdom of Bahrain has not exercised a complete lockdown throughout the COVID19 pandemic, however public health measures like school closure, social distancing, public education and 
extensive testing were taken. The change in public behavior and the reluctance to present to hospital in fear of contacting the virus may explain reductions in STEMI cases. The number of (primary percutaneous coronary intervention) PPCI decreased by $90 \%$ during COVID-19 pandemic (Figure 1d). This has led to other tertiary care hospitals to manage STEMI cases by thrombolysis without referring to the Cardiac Centre, which might be a further reason to the decrease in STEMI admissions at the Cardiac Centre.

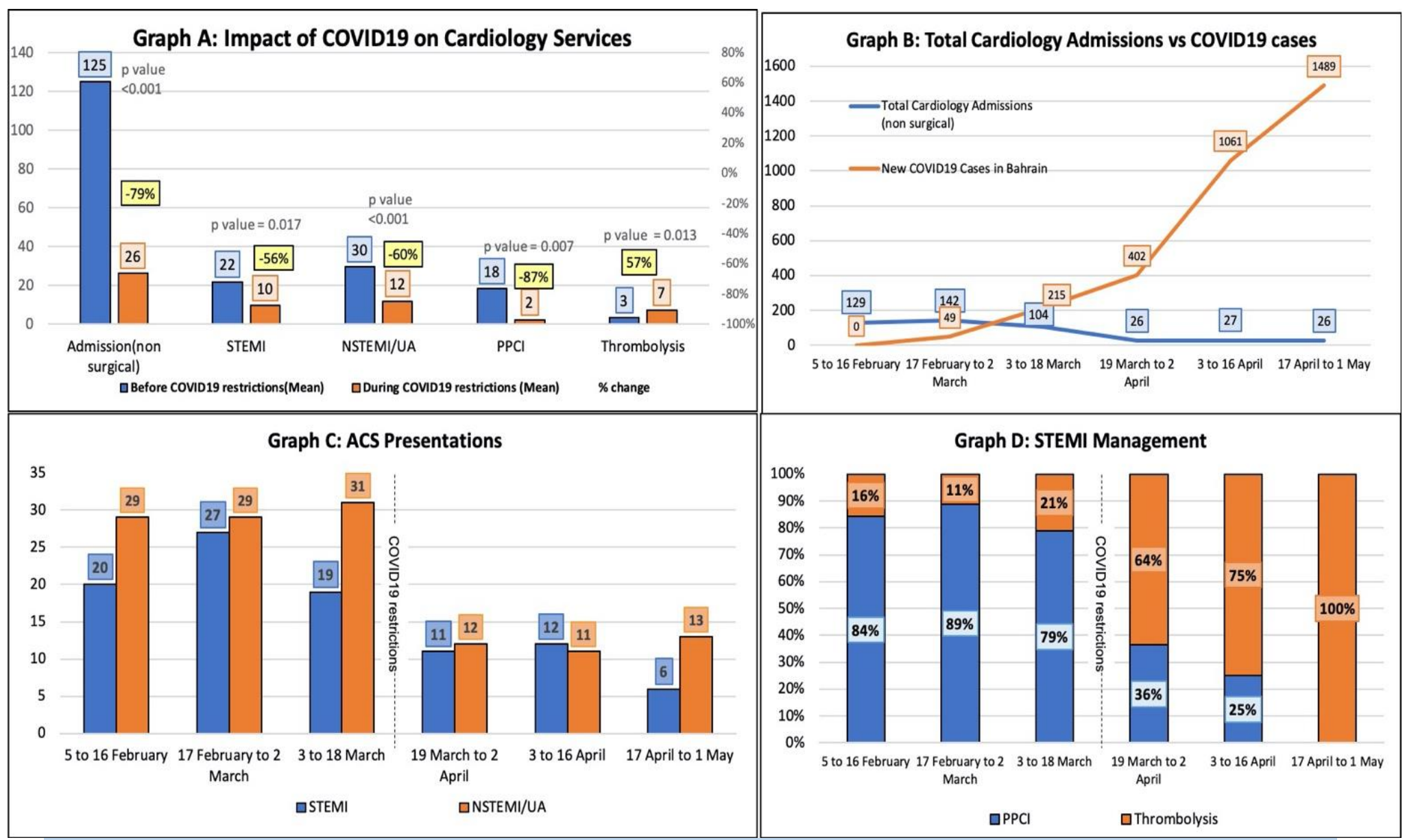

\section{Figure 1}

Impact of COVID -19 pandemic on acute coronary syndrome and management of ST elevation myocardial infarction in Bahrain cardiacmintervention center. A) Mean impact of COVID19 on admission, STEMI presentations and PPCI/ thrombolysis.

B) Total cardiology admissions and COVID19 cases.

C) Total ACS admission to MKCC D) Management of STEMI patient in MKCC. Two sample t test was used to calculate p values (significance level 0.05). Statistical analysis was performed using STATA version 15.1

The data presented has some limitations. This is a retrospective single center study, reporting the initial few weeks before and after the pandemic first hit the Kingdom of Bahrain. Such initial measures taken to limit the virus spread may not be necessary in the future when experience is developed in dealing with COVID19. A balanced approach between measures to limit COVID19 spread, protect the healthcare workers and provide efficient services in managing cardiovascular diseases is essential. Therefore, modification to guidelines in management of STEMI in the COVID-19 era may evolve. Further follow up of the cases managed with current COVID-19 protocols is interesting. Modification to this protocol may help to set up a proper module for future pandemics.

\section{Funding}

Nil 


\section{Conflict of interest}

None

\section{Data Availability}

The data underlying this article will be shared on reasonable request to the corresponding author.

\section{Refrences}

1. Garcia S, Albaghdadi MS, Meraj PM, et al. (2020) Reduction in ST-Segment Elevation Cardiac Catheterization Laboratory
Activations in the United States During COVID-19 Pandemic. $J$ Am Coll Cardiol. 75(22):2871-2872.

2. Metzler B, Siostrzonek P, Binder RK, et al. (2020) Decline of acute coronary syndrome admissions in Austria since the outbreak of COVID-19: the pandemic response causes cardiac collateral damage. Eur Heart J. 41(19):1852-1853.

3. Oriol Rodríguez-Leor, Belén Cid-Álvarez, et al (2020) Impact of the COVID-19 pandemic on interventional cardiology activity in Spain REC Interv Cardiol. 2:82-89 (c) (P)

This work is licensed under Creative

Commons Attribution 4.0 License

To Submit Your Article Click Here: Submit Article

DOI: $10.31579 / 2641-0419 / 077$
Ready to submit your research? Choose Auctores and benefit from:

* fast, convenient online submission

* rigorous peer review by experienced research in your field

* rapid publication on acceptance

* authors retain copyrights

* unique DOI for all articles

* immediate, unrestricted online access

At Auctores, research is always in progress.

Learn more www.auctoresonline.org/journals/clinical-cardiology-andcardiovascular-interventions 